\title{
Cellular leiomyoma with necrosis and mucinous degeneration presenting as pseudo-Meigs' syndrome with elevated CA125
}

\author{
RUIYING DONG*, CHENGJUAN JIN*, QING ZHANG, XINGSHENG YANG and BEIHUA KONG \\ Department of Obstetrics and Gynecology, Qilu Hospital, Shandong University, Jinan, Shandong 250012, P.R. China
}

Received January 6, 2015; Accepted April 2, 2015

DOI: $10.3892 / o r .2015 .3912$

\begin{abstract}
Pseudo-Meigs' syndrome is a syndrome rarely caused by leiomyomas. Elevated CA125 usually suggests malignancy of the ovary. No reported case of pseudo-Meigs' syndrome presenting with necrosis and mucinous degeneration of uterine cellular leiomyomas (CLs) and an elevated CA125 level was found upon a PubMed search. A 37-year-old woman presenting with massive ascites, bilateral pleural effusions and a pelvic mass measuring $20 \times 18 \times 10 \mathrm{~cm}$ is described. The preoperative serum CA125 was $920.4 \mathrm{U} / \mathrm{ml}$. After total abdominal hysterectomy and partial omentumectomy, the final pathologic diagnosis was CL with focal hemorrhage, necrosis and mucinous degeneration. The ascites and pleural effusion disappeared, and the CA125 level returned to normal in one month. Benign leiomyoma accompanied by pseudo-Meigs' syndrome and elevated serum CA125 can mimic a pelvic malignancy.
\end{abstract}

\section{Introduction}

In 1937, Meigs and Cass reported the resolution of hydrothorax and ascites after removal of a benign ovarian mass which attracted widespread attention (1). In 1954, Meigs proposed to restrict Meigs' syndrome to a solid benign ovarian neoplasm such as fibroma or thecoma accompanied by ascites and hydrothorax; the ascites and hydrothorax must resolve fully after removal of the tumor (2). Pseudo-Meigs' syndrome is often characterized by pleural effusion and ascites caused by a pelvic tumor other than an ovarian fibroma (such as struma ovarii tumors, mucinous or serous cystadenomas, germ cell tumors) or uterine leiomyoma (3). Uterine leiomyomas, which are benign tumors of myometrial origin, are the most common gynecological neoplasms, with an estimated prevalence of $25 \%$ in women older than 30 years (4). Leiomyoma variants

Correspondence to: Professor Xingsheng Yang or Professor Beihua Kong, Department of Obstetrics and Gynecology, Qilu Hospital, Shandong University, 107 West Wenhua Road, Jinan, Shandong 250012, P.R. China

E-mail: xingshengyang@sdu.edu.cn

E-mail:kongbeihua@sdu.edu.cn

${ }^{*}$ Contributed equally

Key words: pseudo-Meigs' syndrome, mucinous degeneration, cellular leiomyoma, CA125, necrosis include mitotically active, cellular and atypical leiomyomas. Cellular leiomyomas (CLs) represent a subgroup of leiomyoma variants and are defined by the World Health Organization as typical leiomyomas that exhibit hypercellularity. CLs are rare and do not account for $>5 \%$ of leiomyomas (5). Patients with CLs have a risk of distant metastasis after hysterectomy (6). CA125 is one of the most common tumor markers for pelvic malignancy. Elevated serum CA125 is highly suggestive of epithelial ovarian carcinoma. We here present a case of pseudo-Meigs' syndrome involving hemorrhagic necrosis and mucinous degeneration of a pedunculated subserosal CL associated with an elevated CA125 level.

\section{Case report}

A 37-year-old Chinese woman, gravida 3, para 1, was referred to the gynecology department of our hospital for complaining of right lower abdominal dull pain for 2 years and abdominal distension for 6 days. The patient had cholecystitis for 6 months, but did not seek professional internal medical assistance. Six days before admission, she presented with nausea and abdominal swelling and pain after consuming greasy food. Her condition did not improve after receiving antibiotics. Three days before admission, she came to the emergency room to receive anti-inflammatory, fluid replacement treatment. However, it was not effective. The patient was not taking any medications. She had a regular menstrual cycle and the last menstrual period was December 10. She had not been operated on previously and did not have a family history of breast or gynecologic cancers.

At physical examination she was cachectic, and a massive abdominal mass reaching to the umbilicus was palpated. The examination was difficult due to massive ascites. She had diffuse and rebound tenderness, particularly in the right lower quadrant. Gynecological examination revealed a mass in the right adnexal region with a normal-sized mobile uterus. Laboratory studies showed no abnormalities except for a serum CA125 level of $920.4 \mathrm{U} / \mathrm{ml}$ (normal $<35 \mathrm{U} / \mathrm{ml}$ ). Abdominal and pelvic ultrasound confirmed the presence of ascites and a $16 \times 16 \mathrm{~cm}$ mixed mass at the upper right anterior of the fundus uteri. The mass was heterogeneous in echotexture showing flow signals. A computerized tomographic scan revealed a heterogeneous mass within the pelvis and lower abdomen associated with ascites (Fig. 1A) and massive bilateral hydrothorax resulting in nearly complete collapse of the right middle, right lower and left lower lung lobes (Fig. 1B). 
In order to alleviate the symptoms and aid diagnosis, paracentesis and thoracentesis were performed several times each. The first paracentesis yielded a hematic exudate of 2,900 ml found to be negative for malignant cells and mycobacterium tuberculosis. Five days later, a repeat paracentesis yielded 2,300 $\mathrm{ml}$ of straw-colored fluid containing reactive mesothelial cells without evidence of malignancy. Four days later, a third paracentesis yielded a hematic exudate of 2,900 ml. Thoracentesis was conducted to yield hematic fluid of $1,000 \mathrm{ml}$ consistent with an exudative process. Two days after the thoracentesis, closed thoracic drainage yielded 2,350 $\mathrm{ml}$ of straw-colored fluid.

An exploratory laparotomy was arranged for diagnostic and therapeutic purposes. The patient was found to have $\sim 1,000 \mathrm{ml}$ of hematic ascites and a pedunculated mass protruding from the uterine fundus. The mass was irregular, firm, hemorrhagic, necrotic and dark red in appearance. The pedunculated mass measured 20x18x10 cm in size and the pedicle measured $5 \mathrm{~cm}$ in length and $5 \mathrm{~cm}$ in thickness (Fig. 1C and D). The uterus was found to be enlarged similar to a two-month pregnancy. There was no palpable pelvic or periaortic adenopathy, and the liver, diaphragm, bowel and omentum were grossly free of disease. A frozen section was suggestive of focal necrotic uterine leiomyoma without significant cell atypia. The patient subsequently underwent a total abdominal hysterectomy and omentum sampling. Microscopic examination showed uterine CL with significant hemorrhage, necrosis and mucinous degeneration, adenomyosis, chronic cervicitis and normal omentum (Fig. 2A and B). Mitotic activity, cell atypia, as well as coagulative tumor cell necrosis, were absent. The patient recovered uneventfully and was discharged on day 13, postoperatively. The patient recovered quickly with no evidence of re-accumulation of the pleural effusions or ascites. At one month follow-up, she was clinically well, with no evidence of disease on physical examination and had a normal CA125 level. She remained disease-free both clinically and on repeat CT scan after a follow-up of $>82$ months.

\section{Discussion}

CL with necrosis and mucinous degeneration presenting as pseudo-Meigs' syndrome and highly elevated CA125 is a rare condition. CLs are one of the variant forms of leiomyoma with a favorable long-term prognosis. The most frequent symptoms of CLs are menstrual abnormalities, a pelvic mass, abdominal pain and pelvic pressure. Signs and symptoms of CLs are similar to those of leiomyosarcomas (LMSs), but abdominal pain or distension is much more common in women with LMS. Tumor growth or bleeding may accompany CLs, particularly in postmenopausal women, and these can be signs of a malignancy (7). The recurrence and re-operation rates after myomectomy (28.6 and $14.3 \%$, respectively) in a CL group were found to be similar to those reported for cohorts of patients with ordinary leiomyomas (8). Based on various reports CLs were either the largest or the only uterine mass (9). CLs appear to have a distinct clinical phenotype compared with typical leiomyomas and have various characteristics that typically are associated with LMSs. Similarly to LMSs, CLs were either the largest or the only uterine mass (6).
The distinction of endometrial stromal sarcomas (ESSs) from CLs of the uterus can sometimes be problematic for even the experienced pathologist, since both can show a marked degree of architectural and cytologic similarity, particularly as ESSs can have smooth muscle-like differentiation and CLs, especially highly cellular leiomyomas (HCLs) can exhibit dense cellularity, prominent vascularity and irregular margins (5,10-12). Yet, accurate classification is of considerable importance due to the fact that CL, a benign neoplasm, and ESS, a low-grade malignant neoplasm, are different in clinical behavior and require dissimilar treatment (13).

Immunohistochemistry is currently an essential tool for biomarker detection even in clinical practice. Immunohistochemistry plays an important role for differentiating between CLs and malignant disease. The immunohistochemical detection of CD10, P16, SMA and the smooth muscle marker desmin can be useful for differentiating CLs from ESSs (13).

Interstitial accumulation of mucus within a leiomyoma is refered to as mucinous degeneration (Fig. 2A). Mucinous degeneration is often associated with the most common form of degeneration, hyaline change (14). CL is one of the variant forms of leiomyoma. Compared with surrounding myometrium, CL has an increased number of cells per unit area. The cells of CL have scanty cytoplasm and are closed packed, so the section is dark blue (Fig. 2B). As the immunohistochemical analysis demonstrated positivity for SMA and desmin and lack of CD10 and P16, CL was diagnosed (Fig. 2C-F). With mucinous degeneration, hemorrhage, focal necrosis and abundance of cells, alteration of the normal leiomyoma architecture undoubtedly increases the difficulties in definitive diagnosis and differential diagnosis.

The exact mechanisms of ascites and pleural effusions remain unclear. Potential explanations include: irritation of the peritoneum by the tumor, obstruction of the lymphatics, toxins and release of inflammatory products, hypoalbuminemia, and finally discrepancy between the arterial supply and venous and lymphatic drainage $(15,16)$. Compression and subsequent congestion of the lymphatics and blood vessels throughout the tumor by the tumor itself followed by interstitial fluid secretion from the tumor surface have also been suggested as causes for the development of ascites (17). As for the mechanism of pleural effusions, dye tests have shown that these are likely to originate from the peritoneal fluid via a mechanical transfer through the diaphragmatic opening (15). The connection between uterine leiomyoma and ascites or hydrothorax has been confirmed by the rapid resolution of abdominal and pleural fluid after removal of the tumor.

CA125 is a cell-surface antigen associated with a high molecular weight glycoprotein. High levels of CA125 are mostly noted in pelvic malignancies, such as ovarian cancer with dissemination. However, CA125 does not have $100 \%$ specificity in the diagnosis of epithelial ovarian cancers. Its elevation has also been noted in other malignancies and benign, physiological states, including pregnancy, endometriosis and menstruation (18). In pseudo-Meigs' syndrome, Lin et al (19) and Timmerman et al (20) proposed that elevated CA125 levels are caused by mesothelial expression of CA125 rather than by the fibroma. In addition, in pseudoMeigs' syndrome, it is the peritoneal inflammation not the 

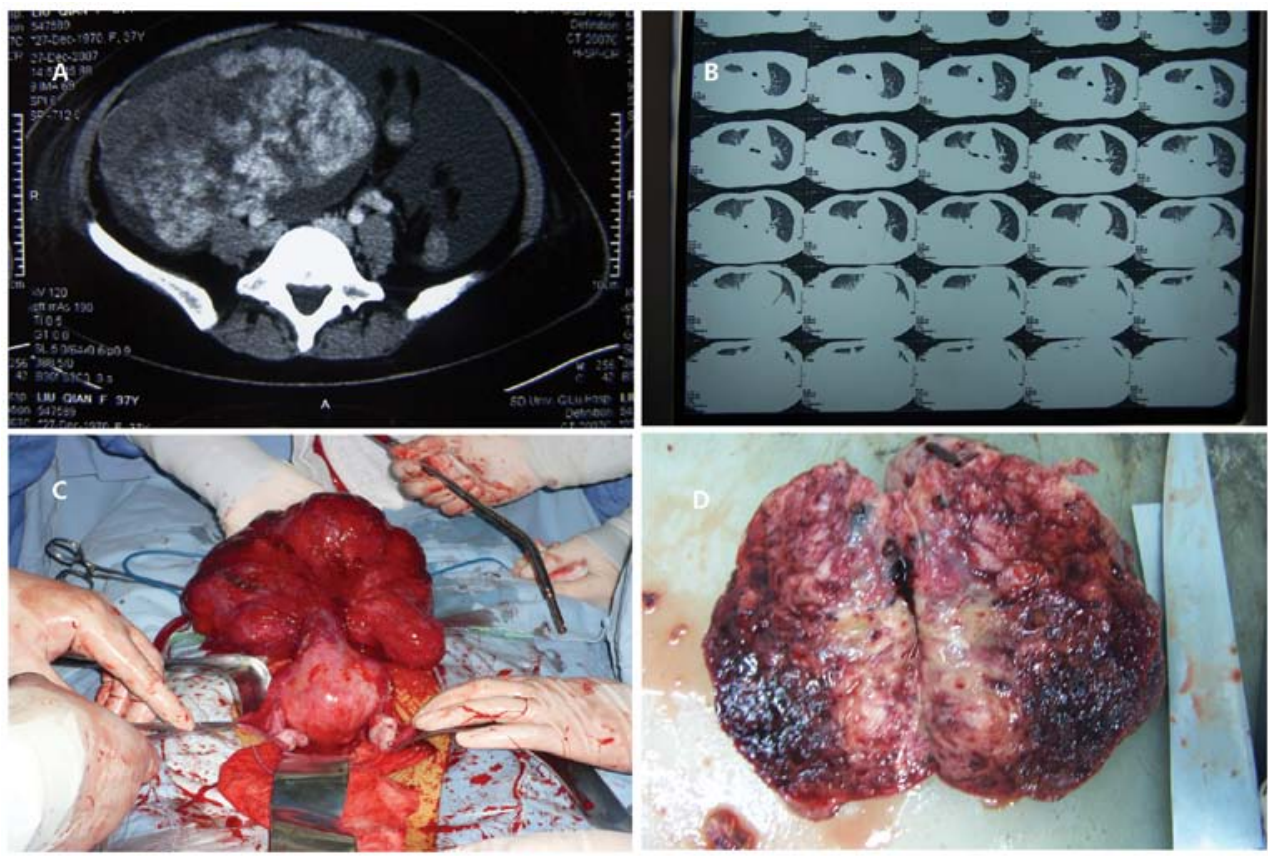

Figure 1. (A) CT scan showed a large heterogeneous tumoral mass measuring $16 \times 16 \mathrm{~cm}$. (B) Nearly complete collapse of the right middle, right lower lung lobes and the left lower lung lobes due to pleural effusion on CT scan. (C) A pedunculated mass measured 20x18x10 cm in size. (D) On extraction of the mass, serous fluid poured from myometrial cysts with significant hemorrhage.
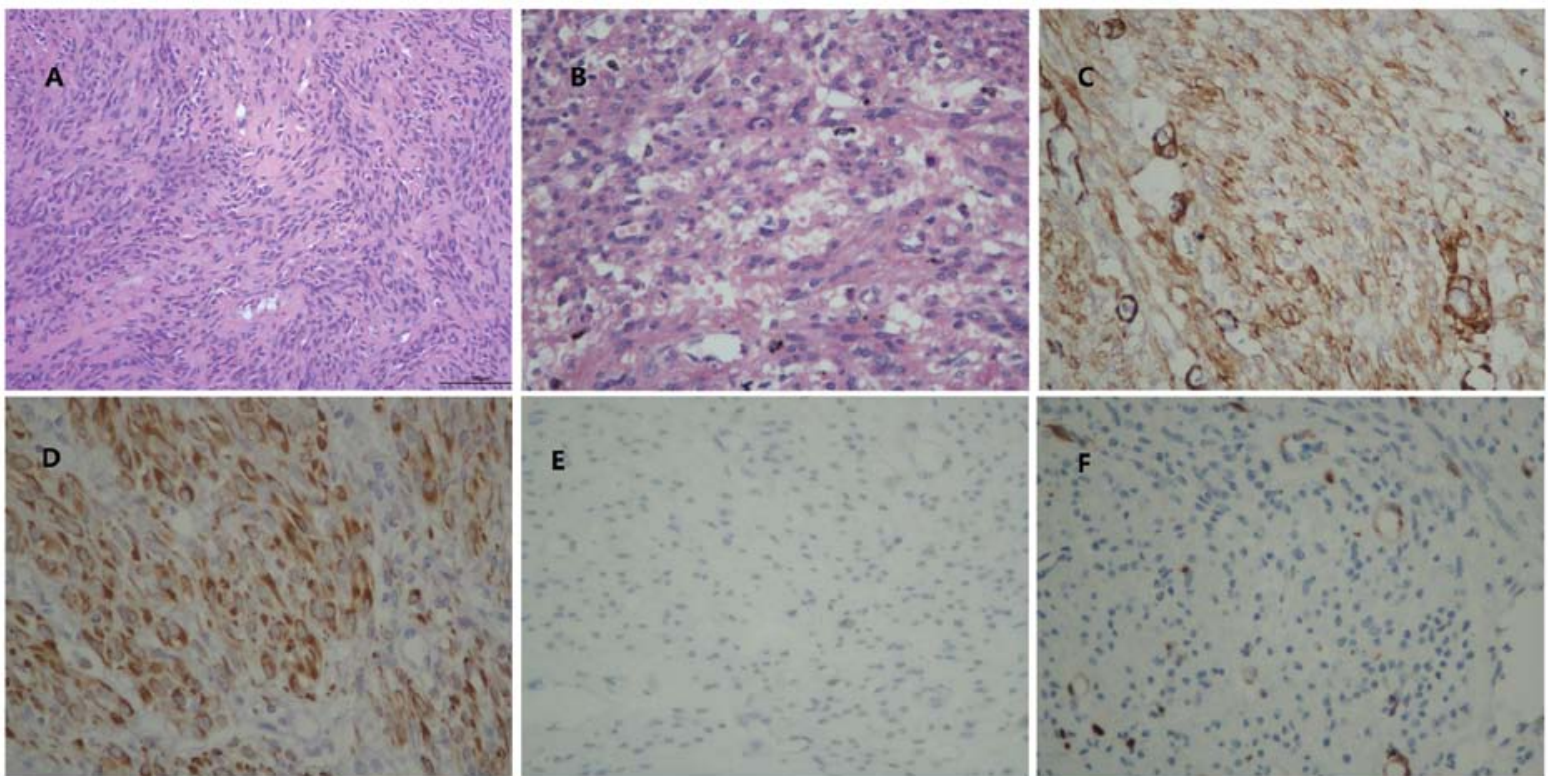

Figure 2. (A) Light microscopy of cellular leiomyoma (hematoxylin and eosin staining). Low-power view shows a typical leiomyoma that exhibits hypercellularity. (B) Light microscopy of cellular leiomyoma (hematoxylin and eosin staining). High-power view shows a leiomyoma composed of abundant cells, lacking fibrous tissue and mitotic figures. (C) SMA-positive expression in muscle tissue. The strong expression of SMA indicates that the mass derived from the myometrium. (D) Desmin-positive expression in muscle tissue. Its positive expression implies that the mass originated in the myometrium. (E) CD10-negative tumor cells. CD10 strong positive expression indicates a malignant neoplasm, such as endometrial stromal sarcoma. (F) P16 focal slightly positive expression, indicating benign differentiation of the mass.

leiomyoma that may be the primary cause of the elevated CA125 level.

Benign leiomyomas presenting with pseudo-Meigs' syndrome and elevated CA125 are rare. Few cases of benign leiomyoma accompanied with pseudo-Meigs' syndrome and elevated CA125 have been described. We performed a systematic review of related literature in the PubMed database using a combination of free words and MeSH. The search was limited to English language literature. Eleven related case reports were found (Tables I and II). Here, we describe a twelfth case with leiomyoma presenting with pseudo-Meigs' syndrome and elevated CA125 level.

Most of the uterine leiomyomas can easily be differentiated from other gynecologic or non-gynecologic pelvic mass 
Table I. General characteristics of reported uterine leiomyomas associated with pseudo-Meigs' syndrome and elevated CA125 level.

\begin{tabular}{|c|c|c|c|c|c|c|c|c|}
\hline Authors (ref.) & Year & $\begin{array}{c}\text { Age } \\
\text { (years) }\end{array}$ & $\begin{array}{l}\text { Tumor size } \\
(\mathrm{cm})\end{array}$ & $\begin{array}{l}\text { Ascites } \\
(\mathrm{ml})\end{array}$ & $\begin{array}{l}\text { Hydrothorax } \\
(\mathrm{ml})\end{array}$ & $\begin{array}{l}\text { CA125 } \\
(\mathrm{U} / \mathrm{ml})\end{array}$ & $\begin{array}{l}\text { Hydrothorax } \\
\text { disappeared } \\
\text { after surgery }\end{array}$ & $\begin{array}{c}\text { Uterine } \\
\text { weight }(\mathrm{g})\end{array}$ \\
\hline Brown et al (21) & 1998 & 31 & $17 \times 11.5 \times 8.5$ & NR & NR & 83.0 & NR & - \\
\hline Domingo et al (22) & 1998 & 46 & 20 in diameter & NR & NR & 317.0 & NR & NR \\
\hline Dunn et al (23) & 1998 & 46 & $30 \times 18 \times 15$ & 1,600 & 3,300 & 254.0 & 4 months & 3,094 \\
\hline Migishima et al (24) & 2000 & 51 & $12.3 \times 24.3 \times 12.5$ & 19,600 & 3,060 & 820.0 & 4 months & 9,700 \\
\hline Amant et al (15) & 2001 & 39 & $30 \times 30 \times 15$ & 12,000 & NR & 785.0 & 7 weeks & 7,840 \\
\hline Kebapci et al (25) & 2002 & 38 & $9 \times 10 \times 10.5$ & NR & NR & 281.0 & 6 months & NR \\
\hline Weise et al (26) & 2002 & 27 & 7x8x6 & 22,500 & NR & 1854.0 & 3 months & - \\
\hline Weinrach et al (27) & 2004 & 40 & $19 \times 11 \times 10$ & NR & NR & 734.0 & 6 months & 1,900 \\
\hline Ricci et al (28) & 2009 & 35 & $15 \times 10 \times 8.5$ & 2,000 & - & 231.4 & - & NR \\
\hline Yip et al (29) & 2014 & 41 & $12 \times 11 \times 7.8$ & 6,600 & - & 939.7 & - & NR \\
\hline Present study & - & 37 & $20 \times 18 \times 10$ & 9,100 & 3,900 & 920.4 & 1 month & NR \\
\hline
\end{tabular}

NR, not reported.

Table II. Clinical symptoms, characteristics and the treatment of reported uterine leiomyomas associated with pseudo-Meigs' syndrome and elevated CA125 level.

\begin{tabular}{|c|c|c|c|}
\hline Authors (ref.) & Clinical symptoms & Pathology & Treatments \\
\hline Brown et al (21) & $\begin{array}{l}\text { Dyspnea, abdominal swelling, } \\
\text { an intermittent difficulty } \\
\text { in passing urine, weight loss }\end{array}$ & Broad ligament leiomyoma & Myoectomy \\
\hline Domingo et al (22) & Respiratory arrest & Multinodular myoma & TAH, BSO \\
\hline Dunn et al (23) & $\begin{array}{l}\text { Nausea, vomiting, } \\
\text { diarrhea, tachypnea }\end{array}$ & $\begin{array}{l}\text { A bilobate, pedunculated } \\
\text { leiomyoma }\end{array}$ & $\begin{array}{l}\text { TAH, BSO, omentectomy, } \\
\text { lymph node sampling }\end{array}$ \\
\hline Migishima et al (24) & $\begin{array}{l}\text { Gradual abdominal distension, } \\
\text { progressive dyspnea }\end{array}$ & $\begin{array}{l}\text { Leiomyoma with myxoid } \\
\text { degeneration and } \\
\text { intercellular edema }\end{array}$ & TAH, BSO \\
\hline Amant et al (15) & Abdomen swelling & A hydropic leiomyoma & TAH \\
\hline Kebapci et al (25) & $\begin{array}{l}\text { Low back pain, } \\
\text { abdominal distension, } \\
\text { weakness, loss of appetite }\end{array}$ & $\begin{array}{l}\text { Pedunculated leiomyoma with } \\
\text { parasitized blood supply } \\
\text { from the omentum }\end{array}$ & $\begin{array}{l}\text { Myoectomy, } \\
\text { omentectomy, } \\
\text { appendectomy }\end{array}$ \\
\hline Weise et al (26) & $\begin{array}{l}\text { Increasing abdominal girth } \\
\text { for } 2 \text { months }\end{array}$ & $\begin{array}{l}\text { Pedunculated fundal myoma } \\
\text { attached to the bladder }\end{array}$ & Myomectomy \\
\hline Weinrach et al (27) & $\begin{array}{l}\text { Abdominal distension, } \\
\text { shortness of breath }\end{array}$ & Uterine symplastic leiomyoma & TAH, BSO \\
\hline Ricci et al (28) & $\begin{array}{l}\text { Abdominal distension } 2 \text { days } \\
\text { after a vaginal delivery }\end{array}$ & Leiomyoma in puerperium & Myoectomy \\
\hline Yip et al (29) & $\begin{array}{l}\text { Abdominal fullness and prolonged } \\
\text { menstrual periods for } 3 \text { years }\end{array}$ & $\begin{array}{l}\text { Pedunculated leiomyoma with } \\
\text { parasitized blood supply from } \\
\text { the adjacent tissues and organs }\end{array}$ & Myoectomy \\
\hline Present & $\begin{array}{l}\text { Right lower abdominal dull pain } \\
\text { and abdominal distension }\end{array}$ & $\begin{array}{l}\text { Cellular leiomyoma with necrosis } \\
\text { and mucinous degeneration }\end{array}$ & TAH, omentum sampling \\
\hline
\end{tabular}

TAH, total abdominal hysterectomy; BSO, bilateral salpingo-oophorectomy.

lesions. However, degeneration, hemorrhage and focal necrosis may make the differential diagnosis difficult, and a degener- ated leiomyoma, HCL, or leiomyoma with edema may not have typical imaging findings (30). 
Our patient demonstrated several unusual features. Firstly, she presented with massive hematic ascites and pleural effusions. Secondly, microscopic examination showed CL with significant hemorrhage, necrosis and mucinous degeneration. Thirdly, we followed up the patient for $>82$ months and she remained disease-free both clinically and on repeat CT scan. A CL should be considered in differential diagnosis when a hypervascular, heterogeneous solid pelvic mass that shows no relation to the uterus is encountered in association with massive ascites, pleural effusion and elevated levels of serum CA125.

\section{References}

1. Meigs JV and Cass J: Fibroma of the ovary with ascites and hydrothorax: with a report of seven cases. Am J Obstet Gynecol 33: 249-267, 1937.

2. Meigs JV: Fibroma of the ovary with ascites and hydrothorax; Meigs' syndrome. Am J Obstet Gynecol 67: 962-985, 1954.

3. Meigs JV: Pelvic tumors other than fibromas of the ovary with ascites and hydrothorax. Obstet Gynecol 3: 471-486, 1954.

4. Solomon LA, Schimp VL, Ali-Fehmi R, Diamond MP and Munkarah AR: Clinical update of smooth muscle tumors of the uterus. J Minim Invasive Gynecol 12: 401-408, 2005.

5. Wilkinson N and Rollason TP: Recent advances in the pathology of smooth muscle tumours of the uterus. Histopathology 39 : 331-341, 2001.

6. Taran FA, Weaver AL, Gostout BS and Stewart EA Understanding cellular leiomyomas: a case-control study. Am J Obstet Gynecol 203: 109.e1-109.e6, 2010.

7. Guan R, Zheng W and Xu M: A retrospective analysis of the clinicopathologic characteristics of uterine cellular leiomyomas in China. Int J Gynaecol Obstet 118: 52-55, 2012.

8. Reed SD, Newton KM, Thompson LB, McCrummen BA and Warolin AK: The incidence of repeat uterine surgery following myomectomy. J Womens Health (Larchmt) 15: 1046-1052, 2006.

9. Schwartz LB, Diamond MP and Schwartz PE: Leiomyosarcomas: clinical presentation. Am J Obstet Gynecol 168: 180-183, 1993.

10. Agoff SN, Grieco VS, Garcia R and Gown AM: Immunohistochemical distinction of endometrial stromal sarcoma and cellular leiomyoma. Appl Immunohistochem Mol Morphol 9: 164-169, 2001.

11. Nucci MR, O'Connell JT, Huettner PC, Cviko A, Sun D and Quade BJ: h-Caldesmon expression effectively distinguishes endometrial stromal tumors from uterine smooth muscle tumors. Am J Surg Pathol 25: 455-463, 2001.

12. Oliva E, Young RH, Amin MB and Clement PB: An immunohistochemical analysis of endometrial stromal and smooth muscle tumors of the uterus: a study of 54 cases emphasizing the importance of using a panel because of overlap in immunoreactivity for individual antibodies. Am J Surg Pathol 26: 403-412, 2002.

13. Zhu XQ, Shi YF, Cheng XD, Zhao CL and Wu YZ: Immunohistochemical markers in differential diagnosis of endometrial stromal sarcoma and cellular leiomyoma. Gynecol Oncol 92: $71-79,2004$
14. Robboy SJ, Bentley RC, Butnor K and Anderson MC: Pathology and pathophysiology of uterine smooth-muscle tumors. Environ Health Perspect 108 (Suppl 5): 779-784, 2000.

15. Amant F, Gabriel C, Timmerman D and Vergote I: Pseudo-Meigs syndrome caused by a hydropic degenerating uterine leiomyoma with elevated CA 125. Gynecol Oncol 83: 153-157, 2001.

16. Zannoni GF, Gallotta V, Legge F, Tarquini E, Scambia G and Ferrandina G: Pseudo-Meigs' syndrome associated with malignant struma ovarii: a case report. Gynecol Oncol 94: 226-228, 2004.

17. Terada S, Suzuki N, Uchide K and Akasofu K: Uterine leiomyoma associated with ascites and hydrothorax. Gynecol Obstet Invest 33: 54-58, 1992.

18. Jacobs I and Bast RC Jr: The CA 125 tumour-associated antigen: a review of the literature. Hum Reprod 4: 1-12, 1989.

19. Lin JY, Angel C and Sickel JZ: Meigs syndrome with elevated serum CA 125. Obstet Gynecol 80: 563-566, 1992.

20. Timmerman D, Moerman P and Vergote I: Meigs' syndrome with elevated serum CA 125 levels: two case reports and review of the literature. Gynecol Oncol 59: 405-408, 1995.

21. Brown RSD, Marley JL and Cassoni AM: Pseudo-Meigs' syndrome due to broad ligament leiomyoma: a mimic of metastatic ovarian carcinoma. Clin Oncol (R Coll Radiol) 10: 198-201, 1998.

22. Domingo P, Montiel JA, Monill JM and Prat J: Pseudo-Meigs syndrome with elevated CA 125 levels. Arch Intern Med 158: 1378-1379, 1998.

23. Dunn JS Jr, Anderson CD, Method MW and Brost BC: Hydropic degenerating leiomyoma presenting as pseudo-Meigs syndrome with elevated CA 125. Obstet Gynecol 92: 648-649, 1998

24. Migishima F, Jobo T, Hata H, Sato R, Ikeda Y, Arai M and Kuramoto H: Uterine leiomyoma causing massive ascites and left pleural effusion with elevated CA 125: a case report. J Obstet Gynaecol Res 26: 283-287, 2000.

25. Kebapci M, Aslan O, Kaya T, Yalcin OT and Ozalp S: Pedunculated uterine leiomyoma associated with pseudo-Meigs syndrome and elevated CA-125 level: CT features. Eur Radiol 12 (Suppl 3): S127-S129, 2002.

26. Weise M, Westphalen S, Fayyazi A, Emons G and Krauss T: Pseudo-Meigs syndrome: uterine leiomyoma with bladder attachment associated with ascites and hydrothorax - a rare case of a rare syndrome. Onkologie 25: 443-446, 2002.

27. Weinrach DM, Wang KL, Keh $\mathrm{P}$ and Sambasiva Rao $\mathrm{M}$ : Pathologic quiz case: a 40-year-old woman with a large pelvic mass, ascites, massive right hydrothorax, and elevated CA 125. Uterine symplastic leiomyoma associated with pseudo-Meigs syndrome and elevated CA 125. Arch Pathol Lab Med 128. 933-934, 2004.

28. Ricci G, Inglese S, Candiotto A, Maso G, Piccoli M, Alberico S and Guaschino S: Ascites in puerperium: a rare case of atypical pseudo-Meigs' syndrome complicating the puerperium. Arch Gynecol Obstet 280: 1033-1037, 2009.

29. Yip HK, Huang LW, Lin YH and Hwang JL: Massive ascites caused by a large pedunculated subserosal uterine leiomyoma that has feeding arteries from peripheral tissues and exhibits elevated CA125: a case report of atypical pseudo-Meigs' syndrome. J Obstet Gynaecol 34: 107, 2014.

30. Ueda H, Togashi K, Konishi I, Kataoka ML, Koyama T, Fujiwara T, Kobayashi H,Fujii S and Konishi J: Unusual appearances of uterine leiomyomas: MR imaging findings and their histopathologic backgrounds. Radiographics 19: S131-S145, 1999. 